\title{
SOBRE O DISCURSO CONSERVADOR: DO REDUCIONISMO DOGMÁTICO AO CETICISMO METODOLÓGICO
}

Thiago Rodrigues

Resumo: A partir da chave da reflexão filosófica, mais especificamente do ceticismo pirrônico, objetiva-se com este artigo ressaltar a necessidade de se assumir uma postura antidogmatizante a fim de evitar o reducionismo dogmático implicado em grande parte do discurso conservador. Nesse sentido torna-se imperativo compreender a reflexão filosófica como uma atividade, em outros termos, como uma prática teórica. Para tanto adotar-se-á a análise de algumas falácias argumentativas correntes no registro do discurso conversador como estratégia argumentativa. Decorre daí o recurso ao ceticismo pirrônico, no registro em que Porchat se apropria dessa teoria, como alternativa necessária aos abusos do discurso dogmático.

Palavras-chave: Filosofia, Ceticismo, Dogmatismo, Falácia, Antidogmatismo.

\begin{abstract}
From the key of philosophical reflection, specifically the Pyrrhonian skepticism purpose is to achieve with this article redeem the need to assume a posture no-dogmatic to avoid the implicated dogmatic reductionism in much of the conservative discourse. In this sense it is imperative to understand the philosophical reflection as an activity, in other words, as a theoretical practice. For that, will be adopted the analyze some current argumentative fallacies in conservative speech record as argumentative strategy.It follows the use of Pyrrhonian skepticism in the record where Porchat appropriates this theory as an alternative needed to dogmatic speech abuses.
\end{abstract}

Keywords: Philosophy, Skepticism, Dogmatism, Fallacy, Anti-dogmatism.

Todo estudante de filosofia aprende logo nas primeiras aulas que certo anti-dogmatismo é imprescindível ao estudo filosófico. O ceticismo metodológico empregado por Descartes em suas

.* Doutorando e mestre em Filosofia pela Universidade Federal de São Paulo (UNIFESP). Professor e Coordenador do curso de Pós Graduação em Filosofia e Pensamento Político Contemporâneos do Centro Universitário Assunção (UNIFAI - SP). 


\section{SOBRE O DISCURSO CONSERVADOR: DO REDUCIONISMO DOGMÁTICO AO CETICISMO METODOLÓGICO \\ Thiago Rodrigues}

Meditações metafísicas constitui página central àqueles que pretendem desenvolver uma abordagem filosófica. Não é possível adentrar no universo da filosofia se adotamos passivamente como certas - verdadeiras - as palavras de nossos maestros. Já dizia Nietzsche, "retribui-se mal a um mestre, continuando-se sempre apenas aluno" (Nietzsche, 1995, p. 20).

No entanto, todo estudante de filosofia sabe também da importância de se estudar nossa herança filosófica. Não se faz filosofia sem o estudo da história da filosofia, mesmo que a atividade filosófica não se reduza aos estudos historiográficos. Não se pode contestar Kant, por exemplo, sem ao menos compreender sua filosofia. E compreender a filosofia kantiana significa também localizá-la no devir filosófico. Desse modo a história da filosofia, no registro da produção brasileira, surge contra certa produção diletante que imperava até então. Sabemos, portanto, da necessidade do estudo sistemático e metódico dos autores que compõem a tradição do pensamento filosófico ${ }^{6}$.

Torna-se imperativo então ressaltar a distinção entre a história da filosofia e a atividade filosófica ${ }^{7}$. É Kant também, na Crítica da Razão Pura, que alerta para a diferença entre filosofia e filosofar. Nesse sentido:

Pode-se apenas aprender a filosofar, isto é, a exercer o talento da razão na aplicação dos seus princípios gerais em certas tentativas que se apresentam, mas sempre com a reserva do direito que a razão tem de procurar esses próprios princípios nas suas fontes e confirmá-los ou rejeitá-los (Kant, 2001, p. 673).

Sendo assim, devemos conhecer as fontes históricas, mas cabe ao exercício da razão confirmá-las ou rejeitá-las, ou seja, a atividade filosófica se caracteriza por um exercício da razão. O que se entrevê aqui é a recusa de todo recurso ao princípio de autoridade como uma forma de fuga ao pensar, no sentido em que fala Hannah Arendt. ${ }^{8}$ Não se faz filosofia aderindo passivamente a uma corrente de pensamento ou a uma retórica inflamada. Desse modo, a atividade filosófica exige o exercício da razão. Em outras palavras, filosofar é adotar certa abordagem metodológica

${ }^{6}$ Àqueles que queiram se aprofundar nesta discussão recomenda-se o instigante livro de Paulo Arantes, Um Departamento Francês em Ultramar. São Paulo: Paz e Terra, 1994.

${ }^{7}$ Não se objetiva aqui adentrar na já esgarçada querela entre a perspectiva hegeliana e a kantiana, como se se tratasse de abordagens antagônicas e excludentes, ao contrário, tomamos como ponto pacífico o necessário imbricamento dessas duas perspectivas.

${ }^{8}$ Pensamos aqui na distinção proposta pela autora em $A$ Vida do Espírito entre conhecer e pensar, sendo, grosso modo, o primeiro a busca da verdade, e o segundo a construção de sentido. Desse modo, embora isso não seja desenvolvido aqui, o exercício filosófico exige essas duas dimensões propostas por Hannah Arendt. 
baseada na investigação, o que leva aquele que se aventura nessa jornada a averiguar os dogmas estabelecidos, e a refletir afim de alcançar suas próprias conclusões para além de toda orientação dogmática.

Durante séculos o magister dixit fez do apelo a autoridade a regra do discurso dogmático, isto é, se o "mestre disse", logo, não se questiona. Durante a Idade Média, por exemplo, apelava-se ao magister dixit que, no caso, se referia à filosofia aristotélica, para impor fim a qualquer divergência possível. É inconteste que muitos dos representantes do discurso conservador na contemporaneidade lançam mão da retórica dogmática como forma de legitimar suas teses. Ora, nada mais contrário ao pensamento filosófico.

Desde Platão - filósofo epistemologicamente dogmático -, que o recurso a retórica é combatido. Aquele que faz uso do discurso inflamado e vazio como única forma de legitimar seu pensamento não pode ser considerado um pensador. E aquele que adere passivamente às suas teses tão pouco. Ouvimos reverberar aqui o sapereau de kantiano, ousa saber, ousa fazer uso do próprio entendimento contra todo e qualquer recurso à autoridade ${ }^{9}$. É preciso pensar por conta própria e se questionar sobre a validade de todo discurso que se apresenta como filosófico.

Isso posto, estamos prontos para tomar como ponto de partida certo discurso corrente na contemporaneidade que exige esses dois erros crassos que contraditam o pensamento filosófico e que foram descritos acima, quais sejam: aceitar passivamente as palavras de seus mentores ou tutores intelectuais; não se prontificar a buscar respaldo na história da filosofia, afinal não devemos reinventar a roda todas as vezes que buscamos pensar sobre algo.

Tomemos alguns exemplos concretos. O suposto maniqueísmo que se apresenta no discurso da maior parte daquilo que ficou conhecido como a nova direita brasileira. De pronto percebemos um recurso retórico simples, o apelo à redução disjuntiva ${ }^{10}$, uma técnica básica de manipulação retórica. Recurso que reduz a argumentação a apenas duas opções possíveis (ou isto ou aquilo, não há outra opção).

Ora, não é preciso muito esforço para perceber que esta tese é de um reducionismo atroz, a realidade não se limita a este maniqueísmo simplista. Por exemplo, a tese que diz: "ou se diminui a idade penal ou colabora-se com a impunidade". É evidente que este reducionismo maniqueísta é falacioso, pois existem diversas nuances possíveis entre essas duas posições antagônicas.

${ }^{9}$ Conferir Kant em Resposta à pergunta: Que é o esclarecimento? Vide referências bibliográficas.

${ }^{10}$ Falácia lógica também conhecida como "falso dilema” ou falácia do terceiro excluído. 


\section{SOBRE O DISCURSO CONSERVADOR: DO REDUCIONISMO DOGMÁTICO AO CETICISMO METODOLÓGICO \\ Thiago Rodrigues}

Ou seja, colocado desta forma o problema parece oferecer apenas duas opções possíveis (ou isto ou aquilo), quando na realidade o problema é muito mais complexo, desse modo dissimula-se todas as outras alternativas, inclusive minimizando a responsabilidade daqueles que deveriam implantar políticas públicas preventivas no que concerne ao problema da violência.

Nossa hipótese fundamental é que por detrás desta técnica retórica, e de outras semelhantes, esconde-se uma postura autoritária que impossibilita o livre exercício da razão, em outras palavras, aquele que se diz portador da verdade exige de seus seguidores que abandonem sua capacidade crítica e aceitem suas teses, por mais absurdas que sejam.

Certa feita, um seguidor ${ }^{11}$ de um desses líderes carismáticos do pseudo-pensamento conservador" ${ }^{12}$, disse que estava "fundamentado na verdade e que não seafastaria deste caminho [...]" É sintomático notar a proximidade entre o que é dito e o recurso ao dogma de fé exigido pelo discurso religioso. Quando falamos de filosofia não se trata de uma adesão incondicional ao dogma de determinado autor. Se assim agimos, já não estamos no registro do pensar. É Santo Agostinho que, ao tratar da fé religiosa, fala da necessidade de evitarmos uma postura protecionista, a fé exige o exercício da fé. Contraditoriamente, a crítica rasteira aos perigos da fé proferida em abjetos discursos pretensamente progressistas, esconde o desejo de uma adesão dogmática ao que é dito. ${ }^{13} \mathrm{~A}$ retórica do discurso dogmático exige a aceitação acrítica da tese defendida. Se ipse dixit, então é verdade.

Um último instrumento retórico corrente que cabe destacar - dentro desse discurso conservador mais rasteiro ${ }^{14}$-é quando seconstrói uma caricatura de um conceito ou do pensamento de determinado autor, para depois criticá-los. Ora, quando isso ocorre, o que é criticado é a caricatura e não o pensamento do autor! Por exemplo, se digo que determinado autor defende a pena de morte e, para tanto, lanço mão de um argumento que o raciocínio do autor não corrobora,

\footnotetext{
${ }^{11}$ Atentemos, se auto-intitula seguidor, logo, não faz uso do próprio entendimento. Subordina-se a figura do tutor, tal como diria Kant.

${ }^{12}$ Cabe ressaltar que nossa crítica se dirige a parte daquilo que foi chamado de discurso conservador, justamente aquela que se enquadra nestes elementos destacados até aqui, o que não implica que todo discurso conservador se configure como pseudo-pensamento.

${ }^{13}$ Note-se que afirmar que determinado discurso é dogmático não implica em dizer que seu opositor também o seja, temos aqui outro mecanismo retórico corrente em certo discurso conservador, afirmar que determinado político é corrupto não implica que seu opositor não o seja, mas quando se suprime esta proposição o leitor é induzido a pensar que ele não o é pelo simples fato de se apresentar como o delator.
}

${ }^{14}$ Vide nota de número 6. 
para depois criticá-lo, logo, o que é criticado não corresponde as ideias do autor, mas àquilo que projetei sobre elas.

Desse modo induzo o leitor a crer que o autor disse algo que na realidade não foi dito. Tomemos um exemplo mais corrente, quando se diz: "todo e qualquer programa político de cunho social deve ser combatido, pois está assentado na extinção da propriedade privada". Sem considerar os equívocos de toda generalização reducionista, vemos claramente que aquilo que é dito deriva de uma distorção caricata das políticas sociais, no entanto induz o leitor mais incauto a aceitar passivamente como verdadeira a tese criticada ${ }^{15}$.

Ao que se propõe aqui, esses exemplos bastam para justificar a defesa do ceticismo metodológico como condição de possibilidade ao exercício filosófico. É pressuposto, por consequência, o entendimento da filosofia como um tipo de atividade investigativa. Visando corroborar esta tese, é pertinente uma breve apresentação da abordagem cética afim de defender a postura anti-dogmatizante como prerrogativa necessária ao bem pensar. Para tanto tomaremos como referência algo do ceticismo pirrônico revisitado pelas análises de Oswaldo Porchat Pereira, sobretudo em A Filosofia e a Visão Comum de Mundo.

Lembremo-nos da célebre oposição levantada pelo intelectualismo clássico - sobretudo Sócrates, Platão e Aristóteles - entre a dóxa e a alétheia, isto é, entre a aparência e a verdade. Está implícito aqui a existência da verdade em oposição ao erro, por consequência, cabe ao filósofo buscar a Verdade universal para além das transitórias certezas particularidades, desse modo a história da filosofia se constitui pela coleção das tentativas dogmáticas de oferecer uma resposta Universal aos problemas fundamentais da existência e do mundo. É desse modo que a tradição filosófica condena à marginalidade aquilo que ficou conhecido como sofística.

Deriva daí, então, o lugar secundário que todas as correntes de orientação céticas de pensamento receberam no decorrer da história do pensamento. Assim, quando falamos da história do pensamento filosófico, é "imediatamente evidente que essa história é, não a história do conflito entre dogmatismo e anti-dogmatismo, mas, precípua e essencialmente, a história das filosofias dogmáticas" (Pereira, 1981, p. 12). Existe, portanto, uma pluralidade de sistemas filosóficos e todos eles igualmente reivindicama Verdade.

\footnotetext{
${ }^{15}$ Falamos de alguns dos recursos retóricos (falácias) recorrentes dentro do discurso de parte da assim chamada nova direita, no entanto poderíamos de pronto elencar uma série de outros recursos igualmente frequentes, por exemplo: causa questionável; apelo ao medo; generalização apressada; apelo a ignorância; culpa por associação; apelo à multidão; ad hominem (retomaremos esta falácia ao final do texto); raciocínio circular (tautológico); “Todo pela parte; parte pelo todo"; etc.
} 
Deriva deste quadro a clássica constatação cética da impossibilidade de qualquer discurso em se afirmar como detentor absoluto da Verdade, instaura-se, desse modo, o "conflito insuperável das filosofias dogmáticas" (Pereira, 1981, p. 11). É justamente a partir desta constatação que defendemos aqui, com Sexto Empírico, a necessidade de adotarmos "a suspensão cética do juízo" (Ibidem) [epokhé] como condição necessária ao exercício da filosofia.

Ecoam imperativas as palavras de Protágoras na letra de seu delator, Platão:

Insisto em que a Verdade é tal como a escrevi, a saber: Cada um de nós é a medida do que é e do que não é, e que um dado indivíduo difere de outro ao infinito, precisamente nisto de serem e de aparecerem de certa forma as coisas para determinada pessoa, e de forma diferente para outra. (Platão, Teeteto, p.28).

Ora, ao se deparar com a constatação de que "a qualquer tese filosófica se pode opor uma outra tese filosófica, de igual força persuasiva e contrária à primeira, de modo que não haveria como aceitar nenhuma das duas" (Smith, 2004, p. 8). Então, o filósofo cético chega à conclusão de que é preciso suspender seu juízo, mesmo que provisoriamente. Desse modo o que vemos nas palavras de Protágoras é que "proposições umas com as outras conflitantes e incompatíveis se lhes propunham à aceitação com igual força persuasiva, tornando-lhes impossível uma opção fundamentada" (Pereira, 1981, p. 11).

Portanto, à postura dogmática se faz necessário adotarmos uma atitude cética como alternativa, já não configura um abuso falar aqui no necessário anti-dogmatismo como um fundamento à atitude filosófica.

Assim, se a sofística colocava em risco a busca pela verdade, o dogmatismo clássico se nos impôs como um obstáculo ainda maior ao exercício filosófico quando surge como fundamento da retórica dogmática. Vejamos, se é condição de possibilidade à qualquer modelo explicativo da realidade e do mundo a Verdade universal, então é justamente porque a verdade tem que existir que posso me lançar nos meandros do discurso retórico, em outras palavras, é porque acredito na verdade que fundamenta determinada corrente filosófica que posso aceita-la como absolutamente verdadeira. É porque são inconciliáveis em última instância que, tal como também afirma Porchat, “duas filosofias em contato são sempre dois mundos que se enfrentam” (Pereira, 1981, p. 18).

Por outro lado, é apenas com a atitude cética que podemos escapar ao recurso à autoridade, pois, se não há a Verdade em que se possa ancorar determinado discurso, é apenas na força argumentativa e lógica inerente ao próprio discurso que devemos buscar recursos para validar ou não as teses defendidas. 
Ora, se não existe a Verdade em algum céu inteligível que possa respaldar minhas teses, elas precisam se justificar por si só, e não apenas isso, qual a garantia que determinada tese válida hoje não perca sua validade no futuro? Isto é, insere-se a validade do discurso no seio do processo histórico. E ainda isso: devo contrapor à minha argumentação aos discursos divergentes visando corroborar minha tese, logo, quando se apresenta algo como verdadeiro é preciso considerar àquelas teorias que se contrapõem à minha argumentação.

Não posso ignorar as objeções levantadas por correntes que partem de pressupostos outros. Ora, se dois fundamentos são inconciliáveis e ambos sólidos, logo não sou capaz de afirmar a Verdade de determinado modelo explicativo em detrimento de outro.

O pressuposto fundamental à nossa argumentação aqui é a impossibilidade, emúltima instância, de todo e qualquer discurso se estabelecer como universal e absoluto. A título de explicitação lancemos mão da posição de Popper $^{16} \mathrm{e}$ o discurso científico. Grosso modo, determinada teoria científica constitui um modelo explicativo para determinado fenômeno, e que é aceita como válida, ao menos até que surja outra teoria capaz de abarcar um número maior de elementos que compõem este fenômeno.

Em outras palavras, toda teoria científica é válida até o momento em que esta possa ser falseada, isto é, substituída por uma teoria de maior alcance ou validade. Nesse sentido podemos dizer que a ciência parece trabalhar mais com a dúvida do que com as certezas, todo cientista - ao menos aqueles que se preocupam com os fundamentos da sua área de conhecimento - sabe das limitações da ciência.

Portanto, a física aristotélica foi válida para explicar o fenômeno da gravidade até que Newton foi capaz de provar a invalidade desse modelo explicativo. No entanto, não significa que a explicação newtoniana seja a Verdade e por isso universal e absoluta. É nesse sentido que o cientista sabe - ou deveria saber - das limitações do discurso da ciência para dar conta da realidade da existência e do mundo. Dentro dessa chave de leitura então, talvez possamos dizer que entre o Big Bang e o Fiat lux os discursos não estejam assim tão distantes.

É justamente nesse sentido, isto é, sobre os limites do discurso científico, que os comentários de João Epifânio Régis de Lima vem nos auxiliar: "Falta-nos luz diante das lâmpadas

\footnotetext{
${ }^{16}$ Cabe frisar que a posição de Popper é considerada como uma teoria da convergência da verdade, desse modo não podemos afirmar que em Popper há a postura cética stricto sensu, tal como defendemos até aqui, ou seja, sobre a impossibilidade de se afirmar o caráter absoluto e universal da verdade (metafísica). No entanto, acreditamos que sua teoria falseacionista vem ao encontro da nossa argumentação e contribui para explicitá-la.
} 
e do fogo. Nossas teorias explicam o acendimento da lâmpada e do fogo, mas não podemos garantir que provem o que de fato neles ocorre, entendendo por 'provar' dar a explicação final, definitiva e verdadeira acerca do fenômeno" (Lima, 2008, p. 104).

O que se vê é a impossibilidade do discurso científico em ascender à Verdade e oferecer um modelo explicativo para determinado fenômeno que seja uma explicação final e definitiva ao fenômeno.

As ciências, agora novamente sob registro pirrônico, não se ocupam do real (fundamento metafísico) das filosofias dogmáticas, mas antes procuram modelos explicativos para determinados fenômenos. Assim:

As tékhnai (ciências) não se preocupam com o Real das filosofias dogmáticas, elas lidam com os fenômenos, que elas observam e sistematizam, procurando detectar suas regularidades e encadeamentos [...] Sobre tal base apoiadas, eles constroem suas previsões e produzem seus ensinamentos, visando o que é útil e benéfico para os homens (Pereira, 2001, p. 60).

Posto isso, estamos prontos para retomar nosso objetivo, qual seja, afirmar a abordagem cética como um exercício metódico necessário a fim de evitar recair na armadilha da retórica dogmática que, se nossa hipótese se sustenta, configura elemento central dentro de certo discurso conservador corrente.

Nesse sentido, quando falamos em abordagem cética, o que se apresenta "é tão somente o filósofo que experiencia dialeticamente a inacessibilidade do absoluto" (Pereira, 2001, p. 57), e que por isso assume "uma postura crítica e suspensiva diante da razão Especulativa" (Pereira, 2001, p. 65). Ou seja, se adotamos, mesmo que metodologicamente, a postura cética diante de uma abordagem dogmática impossibilitamos o apelo ao discurso falacioso. Não é ocioso reiterar que a filosofia adquire dentro deste registro um caráter ativo, isto é, devemos entender a filosofia como uma atividade, desse modo se abordamos filosoficamente determinado discurso devemos assumir a atitude cética como um pressuposto metodológico necessário. $\mathrm{O}$ primeiro passo é suspender o juízo.

Pode-se inclusive afirmar que é preciso "privilegiar a ação sobre a teoria. Ou melhor, tratar o produzir teoria como uma forma particular de ação, como uma prática teórica" (Pereira, 2001, p. 61). A proposta então é postular a filosofia não como um conteúdo - mesmo que o "pensamento pensado" seja necessário ao exercício filosófico - mas antes como um tipo de prática. A atividade filosófica exige, dentro deste registro, a suspensão do juízo como via de acesso 
à prática teórica. Portanto, não é possível pensar filosoficamente sobre determinado discurso sem antes adotar certa conduta anti-dogmatizante.

Por fim, cabe retomar uma última vez um recurso retórico caroà nova direita e à parte do discurso conservador. Certamente, a falácia mais comum dentro deste discurso que buscamos criticar é quando, a fim de desqualificar determinada tese, devia-se a argumentação para um ataque pessoal ao opositor ao invés de rebater sua argumentação. Por exemplo, quando se diz: "Ora, você não é filósofo, logo seu argumento não tem validade". Ou então, quando num debate político, se diz: "não devemos considerar o posicionamento de um político acerca do modelo de família, se ele sequer é casado". Ou ainda, "determinado político é analfabeto, logo seu argumento não tem validade". Ora, em que consiste exatamente essa objeção? Ao argumento, que sequer aparece no enunciado, ou a pessoa?

O fato de ser analfabeto não implica necessariamente que sua argumentação não tenha validade. Tomemos de empréstimo um último exemplo retirado da literatura. Em O Estrangeiro de Albert Camus, após ter participado do enterro de sua mãe sem chorar, Mersault, personagem principal do romance, é condenado por assassinar um homem. Ora, o fato de Mersault não chorar no enterro da própria mãe não significa que ele se torne culpado pelo crime. Qual a relação lógica entre um fato e outro? Em outros termos, se ataco o caráter de uma pessoa e não sua argumentação a fim de desviar deliberativamente a discussão, recaio em um argumento ad hominem, ou seja, numa falácia.

Em contraposição a este tipo de argumentação é preciso assumir, necessariamente, uma postura crítica, ou seja, é imperativo suspender o juízo e pensar. É apenas através do exercício da razão crítica, em consonância com o apelo kantiano, que podemos evitar a tentação de aceitarmos passivamente certo discurso que se apresenta como verdadeiro.

A título de conclusão, remetemo-nos uma última vez às palavras de Porchat Pereira em defesa do necessário recurso a postura cética:

Pois este, no final das contas, não é mais que a necessária consequência do exercício da razão crítica, levado até suas últimas consequências. Por isso mesmo, julgo caber afirmar que o ceticismo se faz o representante mais autêntico, o legatário mais fiel da proposta mais fundamental e mais básica da filosofia do Ocidente (Pereira, 2001, p. 66).

Em suma, dentro desta chave de leitura, fazer filosofia implica necessariamente em assumir certo ceticismo como elemento fundamental à atividade investigativa que melhor o exercício filosófico. E se radicalizarmos essa perspectiva poderíamos inclusive firmar que "a 
oposição conceitual dogmatismo versus ceticismo nos fornece as categorias mais básicas para a reflexão da filosofia sobre si mesma e sobre sua história" (Pereira, 2001, p. 67).

\section{Referências Bibliográficas}

ARENDT, Hannah. A vida do espírito. Tradução de Antônio Abranches e Helena Martins. Rio de Janeiro: Relume-Dumará, 1995.

KANT, Immanuel. Crítica da razão pura. 5. ed. Lisboa: Fundação CalousteGulbenkian, 2001.

. Resposta à pergunta: que é esclarecimento? In: Textos Seletos. Tradução de Floriano de Souza Fernandes. Petrópolis: Editora Vozes, 2008.

LIMA, João Epifânio Régis de. Ce N'est Pas Évident. In: Filosofia e modernidade: reflexão sobre o conhecimento.São Bernardo do Campo: Universidade Metodista de São Paulo, 2008.

NIETZSCHE, Friedrich. Ecce homo: Como alguém se torna o que é. Tradução, notas e posfácio de Paulo César de Souza. São Paulo: Companhia das Letras, 1995.

PEREIRA, Oswaldo Porchat. Ainda é preciso ser cético. Revista Praxis Filosófica. Cali-Colombia, v. 13, p. 53-69, jul./dez. 2001. Disponível em:http://praxis.univalle.edu.co/numeros/n13/oswaldo_porchat pereira.pdf Acesso em: 29 abr. 2015.

O Conflito das Filosofias. In: A Filosofia e a Visão Comum do Mundo. São Paulo: Editora Brasiliense, 1981.

PLATÃO. Teeteto. (Domínio público) Tradução de Carlos Alberto Nunes. Disponível em: http://100medo.com.br/documents/Livros/Teeteto.pdf. Acesso em: 27 abr. 2015.

SMITH, Plínio Junqueira. Ceticismo. Rio de Janeiro: Jorge Zahar, 2004. 